\title{
Development of Alternative Reductant Application in Pressurized Water Reactor Primary Systems*
}

\author{
Masafumi DOMAE**, Hirotaka KAWAMURA** and Taku OHIRA*** \\ ** Central Research Institute of Electric Power Industry \\ 2-6-1 Nagasaka, Yokosuka, Kanagawa 240-0196, Japan \\ E-mail:domae@criepi.denken.or.jp \\ *** The Japan Atomic Power Company \\ 1-1 Kanda-Mitoshirocho, Chiyoda-ku, Tokyo 101-0053, Japan
}

\begin{abstract}
In primary coolant of pressurized water reactors, high concentration dissolved hydrogen (DH) has been added, to prevent generation of oxidizing species through radiolysis of the coolant. Recently, number of ageing plants is increasing and utilities are concerned about primary water stress corrosion cracking (PWSCC). Some researchers consider that occurrence of PWSCC and crack propagation rate are affected by the $\mathrm{DH}$ concentration. The authors consider that one of possible mitigation methods toward PWSCC is use of alternative reductant in place of hydrogen. Because from the radiation chemical aspect aliphatic alcohols are typical scavengers of the oxidizing radical generated through the radiolysis of water, they are promising candidates of the alternative reductant. In the present work, possible alternatives of hydrogen were screened, and methanol was selected as the best candidate. Corrosion tests of type 304 stainless steels were carried out in high temperature water at $320^{\circ} \mathrm{C}$ without irradiation under two conditions: (1) DH 1.5 ppm (part per million) and (2) methanol $2.9 \mathrm{ppm}$. Electrochemical corrosion potential of the stainless steel specimens was measured during the immersion tests. After the immersion tests for $1500 \mathrm{~h}$, surface morphology of the stainless steel specimens was observed by scanning probe microscope. Major component of the oxide film formed on the stainless steel specimens was analyzed by X-ray diffraction. From comparison of the test results, it is concluded that addition of 2.9 ppm methanol has almost the same effect on corrosion environment as DH $1.5 \mathrm{ppm}$ addition.
\end{abstract}

Key words: Pressurized Water Reactor, Primary System, Dissolved Hydrogen, Methanol, Stainless Steel, Electrochemical Corrosion Potential, X Ray Diffraction

\section{Introduction}

At present, dissolved hydrogen (DH) is added to the primary coolant of pressurized water reactors (PWRs), in order to suppress generation of oxidizing species through radiolysis of coolant. Concentration of DH is typically 25 to $30 \mathrm{~cm}^{3} \mathrm{STP} / \mathrm{kg} \mathrm{H}_{2} \mathrm{O}$ in Japanese PWR plants ${ }^{(1)}$. Here, STP means standard temperature and pressure, and 25 and $30 \mathrm{~cm}^{3} \mathrm{STP} / \mathrm{kg} \mathrm{H}_{2} \mathrm{O}$ are equal to 2.2 and $2.7 \mathrm{ppm}$ (part per million), respectively. Recently, it has been pointed out that the presence of lower concentration DH may sufficiently suppress the radiolysis of the coolant ${ }^{(1)}$. Possible benefit of reducing the DH concentration 
is mitigation of primary water stress corrosion cracking (PWSCC) as well as suppression of radioactivity buildup.

Many studies have been carried out on mechanism of PWSCC. It has been pointed out that hydrogen plays an important role in PWSCC ${ }^{(2)}$. According to a recent paper ${ }^{(3)}$, crack propagation rate of PWSCC has a peak around DH $10 \mathrm{~cm}^{3} \mathrm{STP} / \mathrm{kg} \mathrm{H}_{2} \mathrm{O}$. The authors consider that DH is likely one of the most important factors of PWSCC.

Hisamune et al. reported that amount of oxides on fuel claddings in the PWR primary systems was reduced when DH concentration was lowered ${ }^{(4)}$. It is generally considered that radioactive nuclei are generated by neutron irradiation of the corrosion products deposited on the fuel claddings. Therefore, the lower concentration DH may result in reduction of radioactivity in the PWR primary systems.

The authors consider that application of alternative reductant in place of hydrogen possibly suppresses not only PWSCC but also the radioactivity buildup. From aspect of radiation chemistry, it is well known that aliphatic alcohols effectively scavenge $\mathrm{OH}$ radicals that are major oxidizing radicals in the radiolysis of water. That is, aliphatic alcohols are promising candidates of alternative reductants for hydrogen in the PWR primary systems.

In the present work, methanol was selected as the most promising candidate from the screening of possible reductants. In the next step the authors conducted corrosion tests, in order to confirm whether corrosion environment is sufficiently reducing in the presence of methanol. The corrosion tests were carried out under two conditions: DH addition and methanol addition. All experiments were carried out without irradiation. Concerning radiation chemical aspect, effect of methanol addition to the PWR primary system has been investigated by preliminary computer simulation ${ }^{(5)}$.

\section{Screening of reductants}

Possible alternative of hydrogen was investigated. Candidates were simple alcohols and nitrogen compounds as shown in Table 1. For each compound, scores were given from following aspects:

- Number of carbon atoms in a molecule

- Physical properties: melting point and specific gravity

- Legal affairs

- Price

- Continuous supply

- Experience in plants

- Radiation chemical properties

- Reducing power

- Effect on plants

Concerning number of carbon atoms, possible deposition of organic compounds on the fuel claddings was taken into consideration. A compound of less number of carbon atoms is given a better score. Physical properties affect handling of a compound. Legal affairs are state-specific. In the present work, the scores of the legal affairs are based on Japanese domestic laws: (i) fire and disaster management act, (ii) poisonous and deleterious substances control act and (iii) industrial safety and health act. It is considered that a compound regulated by several laws would need more expenses for additional protective facilities. Price and continuous supply were based on the report from a retail vendor of chemicals. A mass deal might improve this score. From aspect of experience, the compounds injected in nuclear plants or power plants up to now were given good scores. Radiation chemical properties mean scavenging power of a compound toward $\mathrm{OH}$ radicals at room temperature. A good score on the radiation chemical properties means an effective $\mathrm{OH}$ radical scavenger. If the rate constants at $320^{\circ} \mathrm{C}$ are evaluated in future, the scores will 
be revised. Reducing power is rather ambiguous. It is assumed that a highly reducing compound may act like hydrogen and induce PWSCC. A reducing compound is given a less favorable score. Effect on plants means a potential load to ion exchange resins. That is, non-ionic compounds are given good scores.

Table 1 Candidates of hydrogen alternative

\begin{tabular}{llr}
\hline \multicolumn{1}{c}{ Compound } & \multicolumn{1}{c}{ Chemical formula } & Total score \\
\hline Methanol & $\mathrm{CH}_{3} \mathrm{OH}$ & 8.06 \\
Ethanol & $\mathrm{CH}_{3} \mathrm{CH}_{2} \mathrm{OH}$ & 55.17 \\
1-Propanol & $\mathrm{CH}_{3} \mathrm{CH}_{2} \mathrm{CH}_{2} \mathrm{OH}$ & 28.67 \\
2-Propanol & $\mathrm{CH}_{3} \mathrm{CHOHCH}_{3}$ & 13.59 \\
1-Butanol & $\mathrm{CH}_{3} \mathrm{CH}_{2} \mathrm{CH}_{2} \mathrm{CH}_{2} \mathrm{OH}$ & 22.64 \\
2-Butanol & $\mathrm{CH}_{3} \mathrm{CH}_{2} \mathrm{CHOHCH}_{3}$ & 70.69 \\
2-Methyl-1-propanol & $\mathrm{CH}_{3} \mathrm{CH}\left(\mathrm{CH}_{3}\right) \mathrm{CH}_{2} \mathrm{OH}$ & 39.60 \\
2-Methyl-2-propanol & $\mathrm{CH}_{3} \mathrm{COH}\left(\mathrm{CH}_{3}\right) \mathrm{CH}_{3}$ & 270.86 \\
Ethylene glycol & $\mathrm{CH}_{2} \mathrm{OHCH} \mathrm{OH}_{2}$ & 11.16 \\
Glycerin & $\mathrm{CH}_{2} \mathrm{OHCHOHCH}$ & 25.92 \\
Ammonia & $\mathrm{NH}_{3}$ & 9.95 \\
Hydrazine & $\mathrm{N}_{2} \mathrm{H}_{4}$ & 38.40 \\
\hline
\end{tabular}

Total score of a compound is defined as the product of all the scores for 12 items above. The total scores are listed in Table 1. According to the present evaluation, methanol is the most promising candidate. Ethylene glycol and ammonia are also promising candidates. As the next step, corrosion test in the presence of methanol was carried out. Details are described below.

\section{Experiments}

In order to evaluate corrosion environment under the $\mathrm{DH}$ condition and the methanol condition, type 304 stainless steel specimens were immersed in high temperature water at $320^{\circ} \mathrm{C}$. To prevent test water from boiling, pressure was controlled at $15 \mathrm{MPa}$. Elemental composition of the stainless steel is shown in Table 2. The surfaces of the specimens were polished with \#1500 SiC paper. The specimens were degreased in an ultrasonic bath using acetone. As an index of the corrosion environment, electrochemical corrosion potential (ECP) was measured at $320^{\circ} \mathrm{C}$. In the ECP measurements, platinum was used as a reference electrode. The platinum electrode works as hydrogen electrode in the presence of DH. After the immersion for $1500 \mathrm{~h}$, the specimens were picked up from the autoclave. The oxide film formed on the specimens was analyzed using scanning probe microscope (SPM) and X-ray diffraction (XRD).

Table 2 Elemental composition of type 304 stainless steel (mass \%)

\begin{tabular}{ccccccccc}
\hline Element & $\mathrm{C}$ & $\mathrm{Si}$ & $\mathrm{Mn}$ & $\mathrm{P}$ & $\mathrm{S}$ & $\mathrm{Ni}$ & $\mathrm{Cr}$ & $\mathrm{Fe}$ \\
\hline Content & 0.05 & 0.4 & 0.82 & 0.027 & 0.002 & 8.3 & 18.19 & Bal. \\
\hline
\end{tabular}

Table 3 Test conditions

\begin{tabular}{cccc}
\hline & DH concentration & Methanol concentration & Immersion time \\
\hline Run 1 & $1.5 \mathrm{ppm}$ & 0 & $1500 \mathrm{~h}$ \\
Run 2* & $150 \mathrm{ppb}$ & $2.9 \mathrm{ppm}$ & $1500 \mathrm{~h}$ \\
\hline
\end{tabular}

*) Up to 1000 h, DH was not added.

Test conditions are shown in Table 3. Run 1 simulates the redox condition of the present PWR primary systems. Although DH concentration in Run 1 is somewhat lower than that 
applied in commercial PWR plants in Japan, Run 1 is control to discuss the effect of the methanol addition. In the present corrosion tests, test water was neutral without addition of borate and lithium. In Run 2, trace $\mathrm{DH}$ as well as methanol was added, in order that platinum electrode worked as hydrogen electrode. Concentration of methanol was decided as follows.

In the radiolysis of water, major oxidizing species is $\mathrm{OH}$ radical. Under the condition of hydrogen addition, hydrogen molecules scavenge $\mathrm{OH}$ radicals through reaction (1).

$\mathrm{OH}+\mathrm{H}_{2} \rightarrow \mathrm{H}_{2} \mathrm{O}+\mathrm{H}$

Methanol also scavenges $\mathrm{OH}$ radicals.

$\mathrm{OH}+\mathrm{CH}_{3} \mathrm{OH} \rightarrow \mathrm{H}_{2} \mathrm{O}+\mathrm{CH}_{3} \mathrm{O}$

Radiation chemical reactions in the PWR primary systems are highly complicated ${ }^{(5)}$. To a first approximation, it is assumed that effect of the $\mathrm{OH}$ radical scavenger can be normalized by the product of concentration of the $\mathrm{OH}$ radical scavenger and rate constant of the scavenging reaction. Methanol concentration should be set so that Eq. (3) is satisfied.

$$
k_{1}\left[\mathrm{H}_{2}\right]=k_{2}\left[\mathrm{CH}_{3} \mathrm{OH}\right]
$$

Here, $\mathrm{k}_{1}$ and $\mathrm{k}_{2}$ are rate constants of reactions (1) and (2), respectively. Reaction rate constant varies with temperature. Temperature dependencies of the rate constants of reactions (1) ${ }^{(6)}$ and (2) ${ }^{(7)}$ have been reported in the form of Arrhenius equation. However, rate constant, $\mathrm{k}_{1}$ increases more slowly with temperature above $230{ }^{\circ} \mathrm{C}$ than expected from Arrhenius equation ${ }^{(8)}$. It is also possible that rate constant, $\mathrm{k}_{2}$ does not follow Arrhenius equation above $300{ }^{\circ} \mathrm{C}$. Anyway, it is difficult to estimate the rate constants above $300{ }^{\circ} \mathrm{C}$ from state of the art. Therefore, methanol concentration which shows the same scavenging capacity toward $\mathrm{OH}$ radicals was calculated based on the reaction rate constants at room temperature. As the results, the methanol concentration is $2.9 \mathrm{ppm}$ (Table 3).

In Run 2, trace hydrogen was also added for the following reason. Above $250{ }^{\circ} \mathrm{C}$, appropriate reference electrode has not been established. Platinum is expected to work as a hydrogen electrode in the presence of DH in constant concentration. In the presence of high concentration $\mathrm{DH}$, effect of the methanol addition would be veiled. On the other hand, it is difficult to control experimentally very low concentration of $\mathrm{DH}$. As a result, the DH concentration was controlled nominally to be $150 \mathrm{ppb}$.

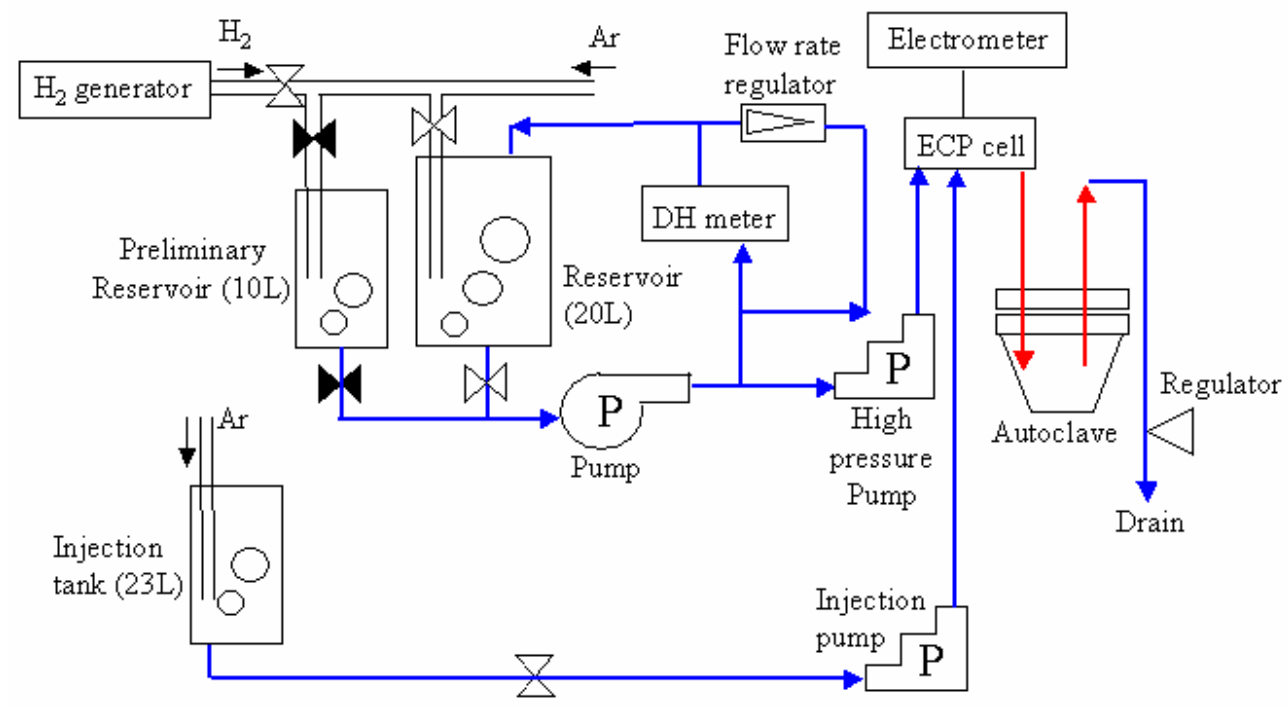

Fig. 1 Figure 1 Schematic diagram of a high temperature water loop system

Figure 1 shows schematic diagram of the high temperature water loop system used in 
the present work. The loop system is once-through type. In Run 1, the injection line which consisted of the injection tank and the injection pump was not used, but test water was fed only from the reservoir to the ECP cell and the autoclave. When the water level in the reservoir was decreased and additional water was supplied, DH concentration was controlled beforehand in the preliminary reservoir and then the water was transferred to the reservoir. The DH concentration was continuously monitored by the DH meter. For the first $1000 \mathrm{~h}$ of Run 2, DH was not added because of a trouble of the hydrogen generator. Methanol solution of $2.9 \mathrm{ppm}$ was bubbled with Ar in the reservoir, and the injection line was not used. For the last $500 \mathrm{~h}$ of Run 2, hydrogen gas was introduced to the reservoir. The $\mathrm{DH}$ concentration of the water in the reservoir was around $1 \mathrm{ppm}$. In the injection tank, the methanol solution of appropriate concentration was bubbled with Ar. Flow rates of the high pressure pump and the injection pump were adjusted, and the DH concentration and the methanol concentration were 0.25 to $0.3 \mathrm{ppm}$ and $2.9 \mathrm{ppm}$, respectively. In all runs, flow rate was $2 \mathrm{~mL} / \mathrm{min}$ at outlet of the water loop system. But, the flow rate varied by around $\pm 10 \%$ during the tests.

In the ECP cell in Fig. 1, the stainless steel electrode and the platinum electrode were sealed with Conax fittings. Both the electrodes were flag type, and electric leads of the same materials were welded. The stainless steel and platinum leads were insulated from each other and the ECP cell. Potential of the stainless steel electrode was measured with an electrometer (KEITHLEY 6514).

The potential of the stainless steel electrode was converted to ECP value based on SHE. Half-cell of SHE is written in Eq. (4).

$$
H_{2}\left(p_{H_{2}}=1 \mathrm{~atm}\right)=2 \mathrm{H}^{+}\left(a_{H^{+}}=1\right)+2 e^{-}
$$

Here, $\mathrm{p}_{\mathrm{H}_{2}}$ is partial pressure of hydrogen equilibrated with the $\mathrm{DH}$ concentration in liquid phase, and $\mathrm{a}_{\mathrm{H}^{+}}$is activity of hydrogen ion in the liquid phase. The half reaction on the platinum electrode in the present experiments is also the same (Eq. (5)). However, hydrogen partial pressure and activity of $\mathrm{H}^{+}$are different.

$$
2 \mathrm{H}^{+}+2 e^{-}=\mathrm{H}_{2}
$$

The potential of the platinum electrode vs. SHE, E(Pt), is written in Eq. (6).

$$
E(P t)=E^{0}\left(2 H^{+} / H_{2}\right)-\frac{R T}{2 F} \ln \frac{p_{H_{2}}}{\left[H^{+}\right]^{2}}
$$

Here, $E^{0}\left(2 \mathrm{H}^{+} / \mathrm{H}_{2}\right)$ is potential of standard hydrogen electrode and is defined as 0 . And, R, T and $\mathrm{F}$ are gas constant, absolute temperature and Faraday constant, respectively. The activity of $\mathrm{H}^{+}$is replaced by concentration of $\mathrm{H}^{+},\left[\mathrm{H}^{+}\right]$, because the concentration of $\mathrm{H}^{+}$ is sufficiently dilute in the present experiments. The partial pressure of hydrogen is calculated using Henry's constant ${ }^{(9)}$. The concentration of $\mathrm{H}^{+}$at $320{ }^{\circ} \mathrm{C}$ is calculated, according to formula of Marshall and Franck ${ }^{(10)}$.

In the present work, the potential of the stainless steel electrode, $\mathrm{E}_{\mathrm{SS}}$, was measured toward the platinum electrode. The ECP vs. SHE of the stainless steel electrode, $\mathrm{E}_{\mathrm{SS}}(\mathrm{SHE})$ is calculated by Eq. (7).

$$
E_{S S}(S H E)=E_{S S}+E(P t)
$$

\section{Results and Discussion}

In Fig. 2, closed circles show time variation of the ECP of the stainless steel electrode during Run 1. The electrochemical corrosion potential of the stainless steel electrode is almost equal to the potential of the platinum electrode. This result can be explained if not only the potential of the platinum electrode but also the ECP of the stainless steel electrode are dominantly influenced by the DH concentration. Probably, cathodic reactions of hydrogen on the platinum surface and the stainless steel surface are rapid, and the ECP is determined by the DH concentration. Closed triangles in Fig. 2 show the ECP vs. SHE of 
the stainless steel electrode, calculated according to Eq. (7). The values of the ECP vs. SHE are lower than $-600 \mathrm{mV}$, which means highly reducing corrosion environment. Figure 3 shows time variation of the ECP of the stainless steel electrode for the first $1000 \mathrm{~h}$ in Run 2. During this period, hydrogen was not added, and ECP vs. SHE cannot be calculated. It is just pointed out that the ECP of the stainless steel electrode is close to the potential of the platinum electrode. Closed circles in Fig. 4 show time variation of the ECP of the stainless steel electrode during the last $500 \mathrm{~h}$ of Run 2 . Around $70 \mathrm{~h}$, the ECP temporarily increased. The reason for this spike was probably ingress of air when water in the preliminary reservoir was transferred to the reservoir. Except the spike, the ECP of the stainless steel is around 0 toward the platinum electrode potential. Closed triangles in Fig. 4 are the ECP vs. SHE of the stainless steel electrode. After $300 \mathrm{~h}$, the ECP values are less than $-600 \mathrm{mV} v s$. SHE, and the corrosion environment is reducing. Steady-state values of the ECP are summarized in Table 4. In both runs, the ECP values are in the range from -620 to $-640 \mathrm{mV}$ vs. SHE. The similar ECP values mean that the corrosion environment in both runs is almost identical.

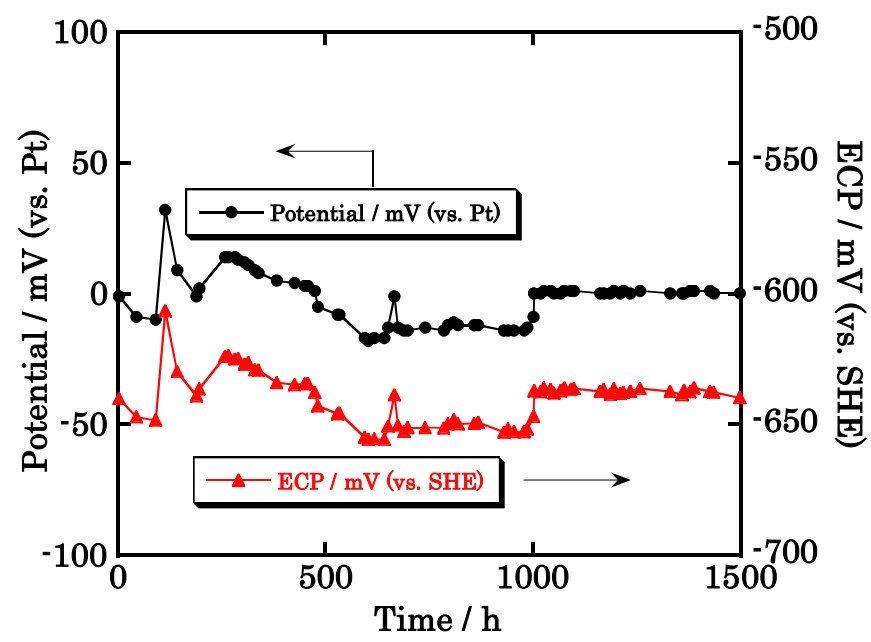

Fig. 2 Time variation of stainless steel potential in Run 1

It might be possible that the low ECP value $v s$. SHE in Run 2 is ascribed not to $2.9 \mathrm{ppm}$ methanol but to trace DH. As described earlier, the addition of trace hydrogen is indispensable to measure the ECP of the stainless steel electrode above $250{ }^{\circ} \mathrm{C}$ and to convert it to SHE-based value. When methanol is added to the primary coolant of PWR, trace $\mathrm{DH}$ is generated through the radiation chemical reaction of methanol with $\mathrm{H}$ atom ${ }^{(5)}$ even if hydrogen is not added. Therefore, it is expected that in the primary coolant of PWRs the ECP of the stainless steel electrode in the presence of $1.5 \mathrm{ppm} \mathrm{DH}$ is in practice similar to that in the presence of $2.9 \mathrm{ppm}$ methanol without hydrogen addition. For further discussion, estimation of hydrogen concentration resulted from the radiation chemical reactions in the PWR primary coolant is needed with high accuracy.

Surface morphology of the stainless steel specimens after the immersion tests was observed by dynamic force microscope (DFM) mode of SPM, and compared in Figs. 5 and 6 . The corrosion products on the stainless steel specimens are sparse after both runs. Surface roughness of both the specimens seems also similar. Comparison of the surface morphology demonstrates that the corrosion environment in both runs is reducing and almost the same. 


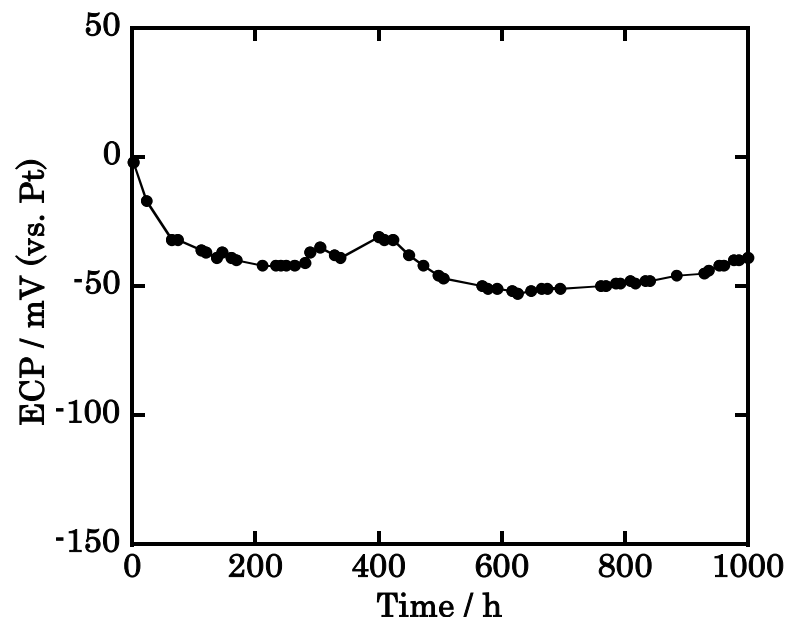

Fig. 3 Time variation of stainless steel potential during first $1000 \mathrm{~h}$ in Run 2

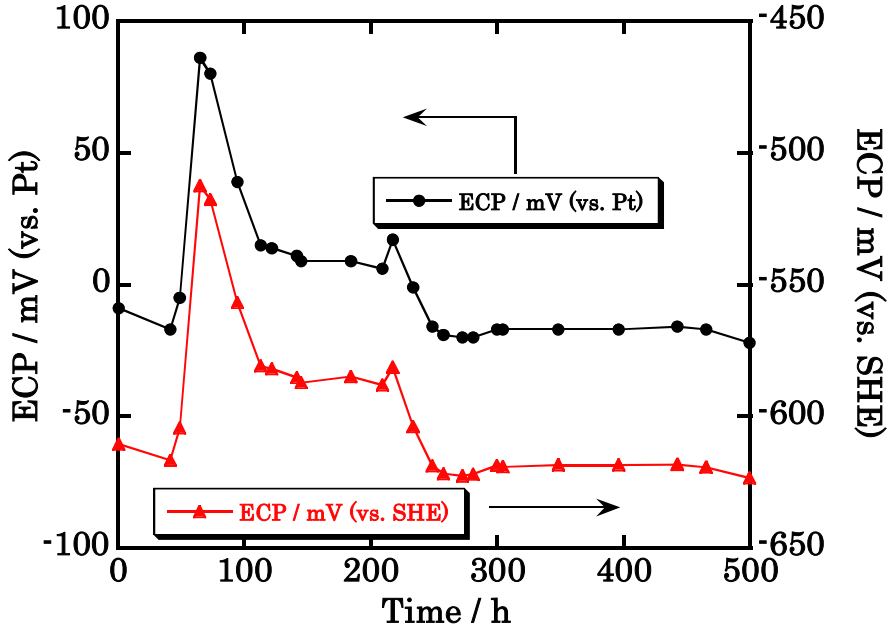

Fig. 4 Time variation of stainless steel potential during last $500 \mathrm{~h}$ in Run 2

Table 4 ECP value at the end of each run

\begin{tabular}{lccc}
\hline & DH concentration & Methanol concentration & Steady-state ECP \\
\hline Run 1 & $1.5 \mathrm{ppm}$ & 0 & $-640 \mathrm{mV}$ vs. SHE \\
Run 2 & $150 \mathrm{ppb}$ & $2.9 \mathrm{ppm}$ & $-620 \mathrm{mV}$ vs. SHE \\
\hline
\end{tabular}




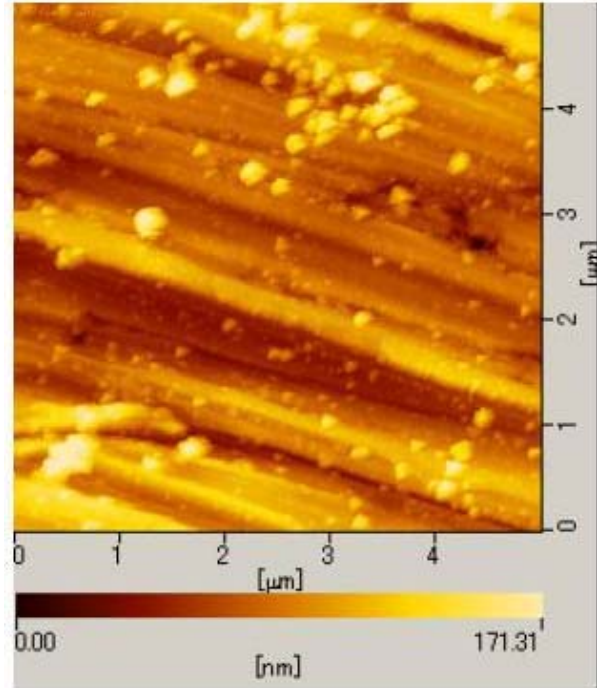

(a)

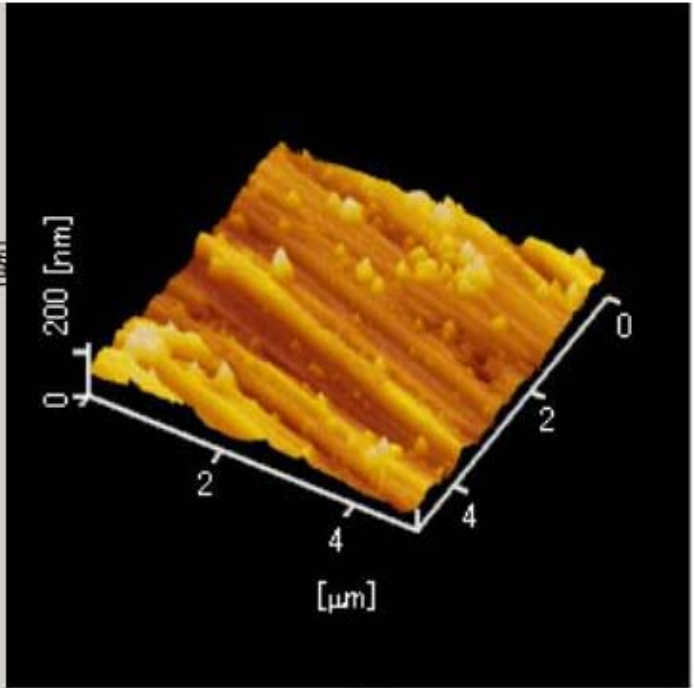

(b)

Fig. 5 Surface morphology (a) and 3-dimension plot (b) of stainless steel specimen after Run 1.

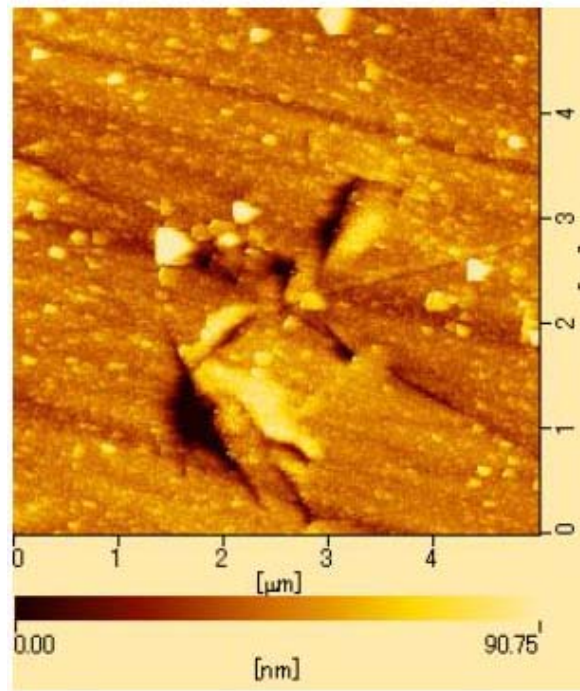

(a)

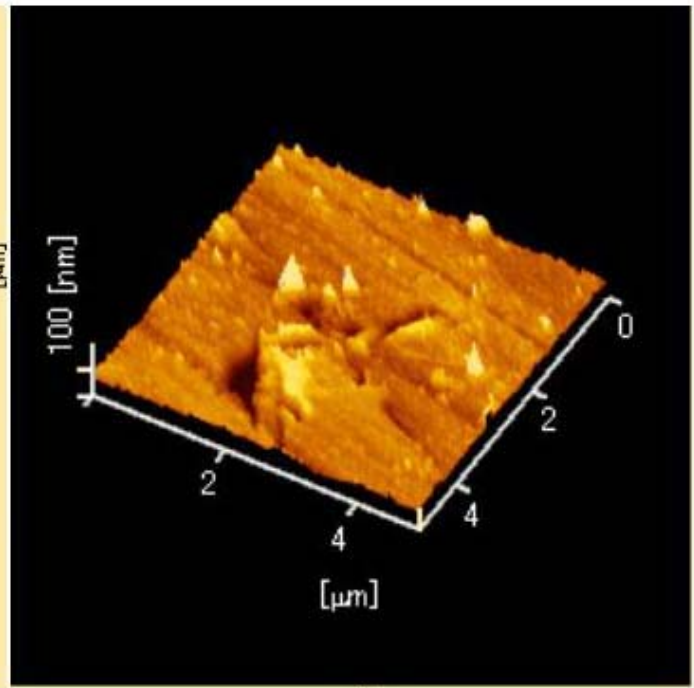

(b)

Fig. 6 Surface morphology (a) and 3-dimension plot (b) of stainless steel specimen after Run 2.

Figure 7 shows XRD patterns of the stainless steel specimens before and after the immersion tests. The XRD patterns after Run 1 is identical to that after Run 2. After Run 1 and Run 2, new XRD peaks appeared and can be attributed to $\mathrm{NiCr}_{2} \mathrm{O}_{4}$. In addition, $\mathrm{FeCr}_{2} \mathrm{O}_{4}$ or $\mathrm{NiFe}_{2} \mathrm{O}_{4}$ might be present. It is difficult to distinguish spinel type oxides by the XRD patterns. Anyway, these oxides are identified in oxide film formed on stainless steels in high temperature water of PWR primary system condition ${ }^{(11)}$. It is considered that the present immersion tests well simulated the PWR primary system condition, although boric acid and lithium hydroxide were not added. 

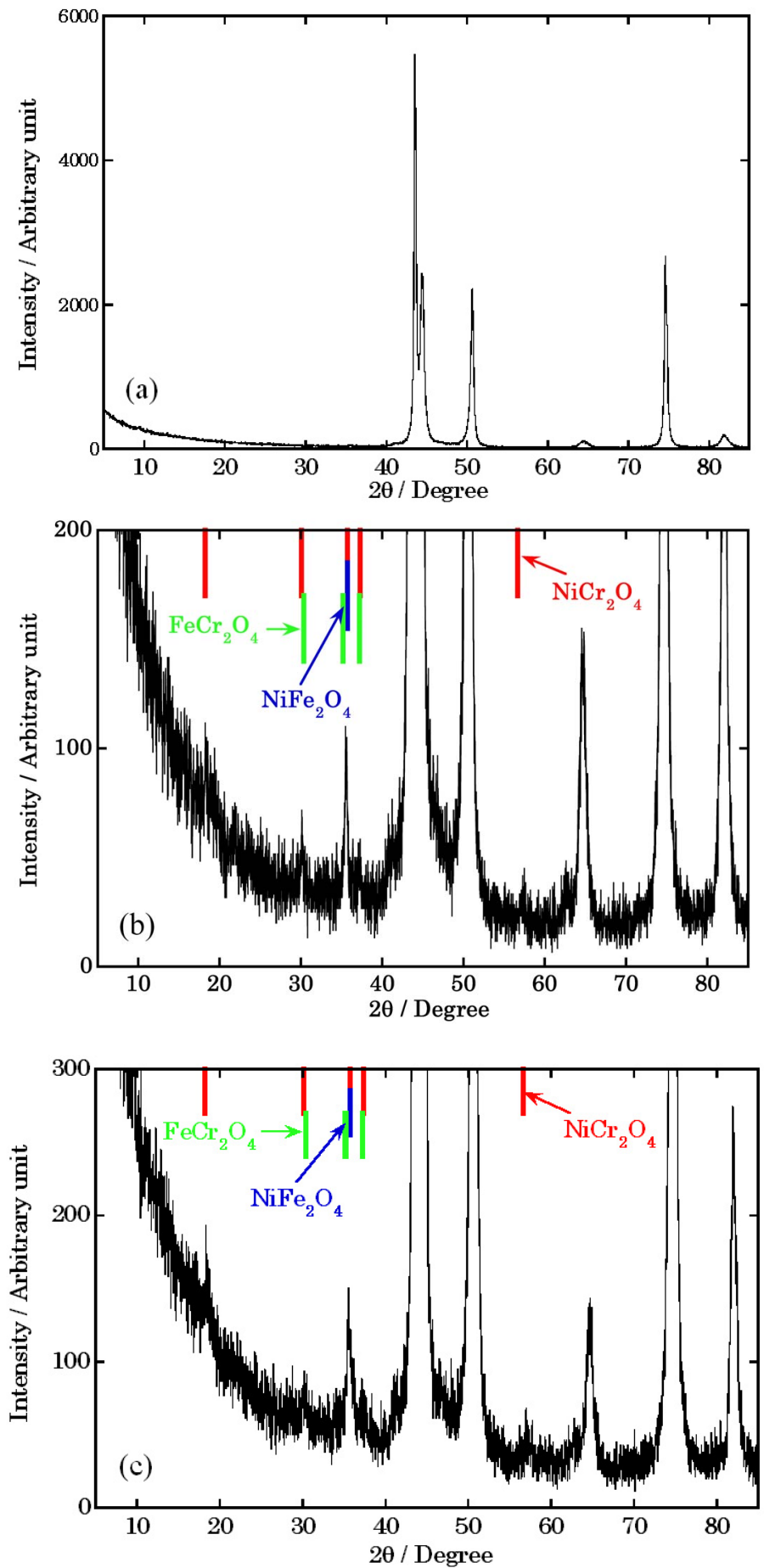

Fig. 7 XRD patterns of stainless steel specimens. (a) before test, (b) after Run 1, (c) after Run 2.

From the above results, it is concluded that the corrosion environment in the presence of methanol $2.9 \mathrm{ppm}$ is almost identical to that in the presence of DH $1.5 \mathrm{ppm}$. In other words, the methanol addition mitigates corrosion environment to the reducing condition similarly to the hydrogen addition. This is the most important conclusion in the present work.

In future, corrosion test under irradiation should be done as a next step. Methanol seems stable and less reactive without irradiation. However, methanol is expected to be a more effective reductant in the presence of irradiation, because reducing radicals are generated 
through reaction (2).

\section{Acknowledgments}

The authors are grateful to Prof. V. M. Byakov at Institute for Theoretical and Experimental Physics in Moscow for his contribution to literature investigation before starting the present research project. The authors also thank Prof. Katsumura at the University of Tokyo for his joining discussion.

\section{References}

(1) Takiguchi, H., Ullberg, M. and Uchida, S., Optimization of Dissolved Hydrogen Concentration for Control of Primary Coolant Radiolysis in Pressurized Water Reactors, Journal of Nuclear Science and Technology, Vol. 41, No. 5 (2004), pp. 601-609.

(2) Totsuka, N., Lunarska, E., Cragnolino, G. and Szklarska-Smialowska, Z., Effect of Hydrogen on the Intergranular Stress Corrosion Cracking of Alloy 600 in High Temperature Aqueous Environments, Corrosion, Vol. 43, No. 8 (1987), pp. 505-514.

(3) Nakagawa, T., Totsuka, N., Terachi, T. and Nakajima, N., Influence of Dissolved Hydrogen on Oxide Film and PWSCC of Alloy 600 in PWR Primary Water, Journal of Nuclear Science and Technology, Vol. 40, No. 1 (2003), pp. 39-43.

(4) Hisamune, K., Sekiguchi, M., Takiguchi, H., New Aspect of DH Control in PWR Primary Water Chemistry, Proceedings of JAIF International Conference on Water Chemistry in Nuclear Power Plants (1998), pp.595-598.

(5) Sunaryo, G. R. and Domae, M., Numerical Simulation on Effect of Methanol Addition on Coolant Radiolysis in Pressurized Water Reactor, Journal of Nuclear Science and Technology, Vol. 45, No. 12 (2008), pp. 1261-1274.

(6) Elliot, A., J., Rate Constants and G-Values of the Simulation of the Radiolysis of Light Water over the Range 0-300 ${ }^{\circ} \mathrm{C}, A E C L-11073$ (1994).

(7) Elliot, A. J. and McCracken, D. R., Effect of Temperature on O-Reactions and Equilibria: A Pulse Radiolysis Study, Radiation Physics and Chemistry, Vol. 33, No. 1 (1989), pp. 69-74.

(8) Marin, T. W., Jonah, C. D. and Bartels, D. M., Reaction of OH Radicals with $\mathrm{H}_{2}$ in Sub-critical Water, Chemical Physics Letters, Vol. 371, No. 1-2 (2003), pp. 144-149.

(9) The International Association for the Properties of Water and Steam, Guideline on the Henry's Constant and Vapor-Liquid Distribution Constant for Gases in $\mathrm{H}_{2} \mathrm{O}$ and $\mathrm{D}_{2} \mathrm{O}$ at High Temperatures, (2004), IAPWS Guidelines, available from < http://www.iapws.org/>, (accessed 2009-09-24).

(10) Marshall, W. L. and Franck, E. U., Ion Product of Water Substance, $0-1000{ }^{\circ} \mathrm{C}, 1$ - 10,000 Bars New International Formulation and Its Background, Journal of Physical and Chemical Reference Data, Vol. 10, No. 2 (1981), pp. 295-304.

(11) Terachi, T., Fujii, K. and Arioka, K., Microstructural Characterization of SCC Crack Tip and Oxide Film for SUS316 Stainless Steel in Simulated PWR Primary Water at $320{ }^{\circ} \mathrm{C}$, Journal of Nuclear Science and Technology, Vol. 42, No. 2 (2005), pp. 225-232. 